\title{
Morphology and properties of polypropylene/ethylene vinyl acetate copolymer/wood powder blend composites
}

\author{
D. G. Dikobe*, A. S. Luyt \\ Department of Chemistry, University of the Free State (Qwaqwa Campus), Private Bag X13, Phuthaditjhaba, 9866, \\ Republic of South Africa
}

Received 25 Novenber 2008; accepted in revised form 16 February 2009

\begin{abstract}
Polypropylene (PP) was blended with ethylene vinyl acetate copolymer (EVA) to form PP/EVA polymer blends. Wood powder (WP) was mixed into these blends at different weight fractions (50/50/0, 45/45/10, 40/40/20, 35/35/30 w/w $\mathrm{PP} / \mathrm{EVA} / \mathrm{WP}$ ) to form PP/EVA/WP blend composites. The morphology, as well as thermal and mechanical properties, of these composites were investigated. The scanning electron microscopy (SEM) and differential scanning calorimetry (DSC) results confirm the immiscibility of EVA and PP in the blends, and show that WP is primarily concentrated in the EVA phase. DSC results further show that the EVA crystallization behaviour is significantly influenced by the presence of WP. Dynamic mechanical analysis (DMA) results confirm immiscibility of PP and EVA, as well as an interaction between EVA and WP. Interaction between EVA and WP was further confirmed by Fourier-Transform infrared spectroscopy (FTIR). TGA results show that the blend composite degradation was also influenced by the presence of WP.
\end{abstract}

Keywords: polymer composites, polymer blends, polypropylene, ethylene vinyl acetate copolymer, wood powder

\section{Introduction}

Polymer blending, which is a very important technique in industrial practices, is performed to achieve specific properties such as improved mechanical properties that individual materials do not possess [1,2]. Polymers can be blended directly by simply mixing them under specific conditions, or by using appropriate compatibilizers. Polymer blending has the following advantages: cheap, easily processable, and specific properties can be achieved depending on the composition and preparation methods [1-4].

PP is one of the most important commodity polymers and is used in many areas, such as home appliances, automotive parts, construction and other important industrial applications. PP's applications are often limited due to its low impact strength and Young's modulus properties, particu- larly at low temperatures and high temperature loading conditions. Blending PP with different polymers is an economic and effective way to improve these drawbacks [5-8].

EVA with different VA contents (16 and 28 wt\%) have been blended with PP to enhance PP's low impact strength. The following observations on PP/EVA blending have already been reported [5, $9,10]:$

- Two melting peaks and two glass transition peaks were observed indicating that PP/EVA blends are thermodynamically immiscible and also technologically non-compatible.

- A co-continuous phase was observed in blends with an EVA content of $50 \mathrm{wt} \%$ or higher.

- A mechanical locking interphase was found if the blend was kept below the crystallization temperature of PP. 
- Partial compatibility was achieved by the addition of a crosslinking agent.

- EVA acts as a good impact modifier.

- When a PP/EVA blend was irradiated, chain scission was initiated in the PP phase, while crosslinking prevailed in the EVA phase.

Most polymer blends are immiscible on a molecular scale and form heterogeneous systems that affect their properties. One way of improving the properties of the blends is to introduce fillers into the systems [11-13]. Addition of fillers is favoured because it is a cheap, effective and a fast method to modify the properties of the base material. The degree of improvement often depends on the type of the filler (synthetic or natural), particle size and shape, filler content, and surface treatment which promotes interaction between the filler and the polymer matrix [5, 7].

The need for non-toxic and environmentally friendly materials favours the use of natural fibres, over inorganic and synthetic fillers, as fillers in polymeric materials. Dikobe and Luyt [14] and other researchers used lignocelluosic fillers as reinforcing material in different polymer matrices [15-20].

Although there is extensive literature on the use of natural fillers in single polymers [14-18, 21-26], there are only a few studies dealing with polymer blends filled with natural fillers. Espert et al. [20] compared water absorption of natural cellulosic fibres from wood and one-year crops in polypropylene composites, as well as their influence on the mechanical properties of the composites. They reported that the use of a post-consumer polypropylene with a low percentage of EVA in its composition in some cases leads to improved resistance to water absorption and better mechanical properties, and that EVA can further improve the compatibility between the fibres and the matrix.

The purpose of this study was to investigate the morphology and properties of PP/EVA binary blends and PP/EVA/WP polymer blend composite ternary systems. The paper reports on the effect of WP content on the morphology and properties of the polymer blend. We were interested in establishing the location of WP in these composites, and how this would influence the thermal and mechanical properties of these systems.

\section{Materials and methods}

PP, supplied by Sasol Polymers, South Africa, has a density of $0.90 \mathrm{~g} \cdot \mathrm{cm}^{-3}$, a melting point of $165^{\circ} \mathrm{C}$, a tensile strength of $30 \mathrm{MPa}$ and a melt flow index of $12 \mathrm{~g} / 10 \mathrm{~min}\left(230^{\circ} \mathrm{C}, 2.16 \mathrm{~kg}\right)$. EVA with $9 \%$ vinyl acetate (VA) content, supplied by Plastamid, Elsies River, South Africa, has a density of $0.93 \mathrm{~g} \cdot \mathrm{cm}^{-3}$, a melting point of $95^{\circ} \mathrm{C}$, melt flow index of $2.5 \mathrm{~g} / 10 \mathrm{~min}\left(80^{\circ} \mathrm{C} ; 2.16 \mathrm{~kg}\right)$, a tensile strength of $19 \mathrm{MPa}$ and a $750 \%$ elongation at break. Pine WP, or pine saw dust, was obtained from FBW Taurus, Phuthaditjhaba, South Africa. WP, supplied as a light orange coloured powder with a density of $1.5 \mathrm{~g} \cdot \mathrm{cm}^{-3}$ was dried at $120^{\circ} \mathrm{C}$ for 48 hours. Particles with sizes $\leq 150 \mu \mathrm{m}$ were obtained by sieving the dried WP using laboratory test sieves of $150 \mu \mathrm{m}$ pore size.

Blends and blend composites were weighed according to the required ratios $(100 / 0 / 0,0 / 100 / 0$, $50 / 50 / 0,45 / 45 / 10,40 / 40 / 20$ and 35/35/30 w/w $\mathrm{PP} / \mathrm{EVA} / \mathrm{WP}$ ) to make up a total of $38 \mathrm{~g}$ (which is the mass required for thoroughly mixing the different components in the Brabender Plastograph mixer). Mixing of the samples was done at a temperature of $180^{\circ} \mathrm{C}$ and a mixing speed of $30 \mathrm{rpm}$ for 15 minutes. The samples were then melt pressed at $190^{\circ} \mathrm{C}$ and 100 bar for 3 minutes. The pressed samples were allowed to cool at room temperature for 10 minutes before touching them to avoid air from penetrating, which would promote the formation of bubbles.

DSC analyses were carried out in a Perkin Elmer DSC7 differential scanning calorimeter (Wellesley, Massachusetts, USA) under flowing nitrogen $\left(20 \mathrm{ml} \cdot \mathrm{min}^{-1}\right)$. Samples with masses of approximately $7.5 \mathrm{mg}$ were heated from 25 to $190^{\circ} \mathrm{C}$ at a rate of $10^{\circ} \mathrm{C} \cdot \mathrm{min}^{-1}$ in order to eliminate the thermal history, cooled to $25^{\circ} \mathrm{C}$ at $2^{\circ} \mathrm{C} \cdot \mathrm{min}^{-1}$ and reheated under the same conditions. For each sample the melting and crystallization data were obtained from the second scan.

The morphologies of the 50/50 w/w PP/EVA blend and the 40/40/20 w/w PP/EVA/WP composite were examined using a Shimadzu 5SX-550 Superscan scanning electron microscope. The samples were immersed in liquid nitrogen to ensure perfect breakage. The fractured surface was sputter coated with gold dust $(60 \mathrm{~nm})$ before viewing. 
A careful separation of the polymers was performed by selective Soxhlet solvent extraction. The EVA in the 50/50 w/w PP/EVA blend and the 40/40/20 w/w PP/EVA/WP blend composite were extracted using $\mathrm{n}$-heptane at $20^{\circ} \mathrm{C}$ for 24 hours. The residues from these samples were dried in an oven at $50^{\circ} \mathrm{C}$ for $24 \mathrm{~h}$. The dried samples were sputter coated with gold dust $(60 \mathrm{~nm})$ and SEM micrographs were obtained using a Shimadzu 5SX-550 Superscan scanning electron microscope.

For DMA analysis, rectangular samples of $20 \mathrm{~mm} \times 5 \mathrm{~mm} \times 0.5 \mathrm{~mm}$ were used. A Perkin Elmer Diamond DMA was used for the evaluation of the storage modulus, loss modulus and mechanical damping factor. The temperature range over which the properties were measured was -100 to $100^{\circ} \mathrm{C}$ at a heating rate of $5^{\circ} \mathrm{C} \cdot \mathrm{min}^{-1}$ under $30 \mathrm{ml} \cdot \mathrm{min}^{-1}$ flowing nitrogen. The tests were carried out at a frequency of $1 \mathrm{~Hz}$.

FTIR microscopy was performed using a Perkin Elmer Precisely Multiscope. Very thin samples were placed under the microscope, and microscope photos as well as FTIR spectra of the desired areas were collected. The samples were scanned using a Perkin Elmer Spectrum 100 FTIR spectrometer over $400-4000 \mathrm{~cm}^{-1}$ at a resolution of $4 \mathrm{~cm}^{-1}$.

Thermogravimetric analyses (TGA) were carried out on a Pelkin-Elmer TGA7 thermogravimetric analyzer. Samples having a mass of approximately $7 \mathrm{mg}$ were heated from 25 to $600^{\circ} \mathrm{C}$ at $20^{\circ} \mathrm{C} \cdot \mathrm{min}^{-1}$ under flowing nitrogen $\left(20 \mathrm{ml} \cdot \mathrm{min}^{-1}\right)$.

Tensile testing was performed under ambient conditions on a Hounsfield H5KS universal tester at a cross-head speed of $50 \mathrm{~mm} \cdot \mathrm{min}^{-1}$. Tensile test specimens (gauge length $24 \mathrm{~mm}$, width $5 \mathrm{~mm}$, thickness $2 \mathrm{~mm}$ ) were prepared using a dumbbell shaped hollow die punch. Six samples per composition were analysed. A statistics computer programme was used to eliminate out-of-range values, and the mean of the accepted values was reported.
The tensile strength, Young's modulus, and elongation at break values were obtained from this testing.

\section{Results and discussion}

The DSC curves in Figure 1 show endothermic melting peaks at $99^{\circ} \mathrm{C}$ for EVA and $165^{\circ} \mathrm{C}$ for PP. The PP/EVA blend has two melting peaks at 99 and $168^{\circ} \mathrm{C}$, indicating immiscibility of EVA and PP. The WP blend composites show a decrease in EVA melting point to $86^{\circ} \mathrm{C}$, while the PP melting point remains around $166^{\circ} \mathrm{C}$. Decreasing amounts of EVA and PP gave rise to decreasing melting enthalpies (Table 1). This was to be expected, since the melting enthalpies are related to the amounts of polymer in the sample, and since the amounts of polymer decrease with increasing WP content in the sample, the melting peak sizes and related enthalpies should correspondingly decrease. It is, however, possible that the presence of solid filler may influence the crystallization behaviour of either or both polymers, and it was decided to compare the experimentally observed enthalpy values with calculated enthalpy values. These values were calculated assuming that the composites were com-

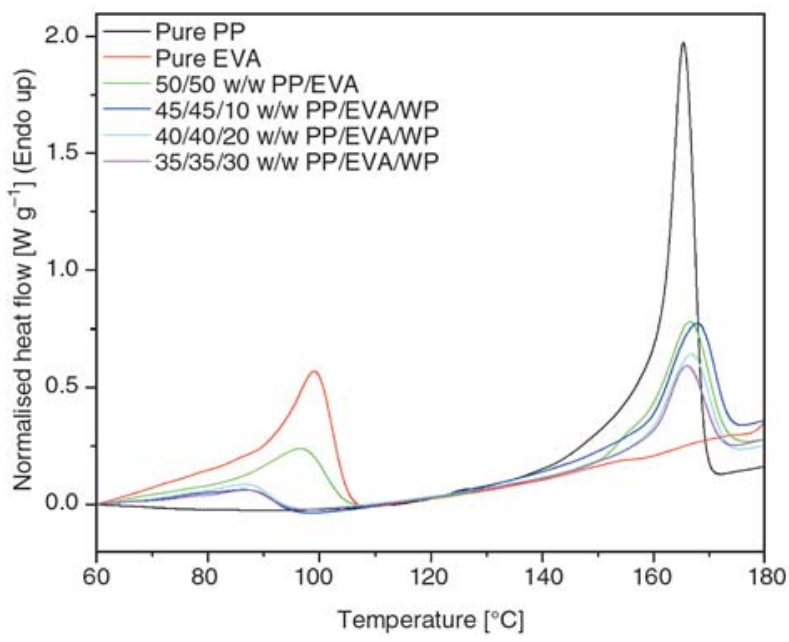

Figure 1. DSC heating curves of pure EVA, pure PP and $\mathrm{PP} / \mathrm{EVA} / \mathrm{WP}$ blend composites

Table 1. DSC melting data for pure PP, pure EVA and their blend composites $\left(2^{\circ} \mathrm{C} \cdot \mathrm{min}^{-1}\right.$ cooling $)$

\begin{tabular}{|c|c|c|c|c|c|c|}
\hline \multirow{2}{*}{$\begin{array}{c}\text { PP/EVA/WP } \\
{[w / w]}\end{array}$} & \multicolumn{2}{|c|}{$\mathbf{T}_{\text {Peak }}\left[{ }^{\circ} \mathbf{C}\right]$} & \multicolumn{2}{|c|}{$\Delta \mathbf{H}_{\text {obs }}\left[J \cdot g^{-1}\right]$} & \multicolumn{2}{|c|}{$\Delta \mathbf{H}_{\text {calc }}\left[\mathbf{J} \cdot \mathrm{g}^{-1}\right]$} \\
\hline & EVA & PP & EVA & PP & EVA & PP \\
\hline $100 / 0 / 0$ & - & $165.3 \pm 7.3$ & - & $82.3 \pm 4.2$ & - & $82.3 \pm 4.2$ \\
\hline $0 / 100 / 0$ & $99.3 \pm 3.5$ & - & $54.2 \pm 1.2$ & - & $54.2 \pm 1.2$ & - \\
\hline $50 / 50 / 0$ & $99.7 \pm 2.4$ & $168.1 \pm 6.4$ & $26.9 \pm 1.5$ & $38.7 \pm 3.1$ & $27.1 \pm 2.6$ & $41.2 \pm 0.9$ \\
\hline $45 / 45 / 10$ & $85.5 \pm 2.9$ & $167.5 \pm 6.2$ & $10.2 \pm 1.2$ & $35.8 \pm 3.4$ & $24.4 \pm 2.4$ & $37.0 \pm 0.5$ \\
\hline $40 / 40 / 20$ & $86.1 \pm 3.2$ & $166.9 \pm 5.4$ & $9.8 \pm 0.7$ & $31.4 \pm 2.5$ & $21.7 \pm 1.4$ & $32.7 \pm 0.5$ \\
\hline $35 / 35 / 30$ & $86.2 \pm 3.6$ & $165.8 \pm 4.3$ & $6.7 \pm 0.5$ & $26.9 \pm 1.9$ & $18.9 \pm 1.2$ & $28.8 \pm 0.9$ \\
\hline
\end{tabular}


pletely homogeneous and that neither blending nor the presence of WP changed the crystallization characteristics of either polymer. Table 1 shows that there is a good correlation between the experimentally observed and theoretically calculated enthalpies for both PP and EVA in the 50/50 w/w PP/EVA blend. This confirms that a completely immiscible blend was formed, and that neither polymer had an influence on the crystallization behaviour of the other polymer. Further support for this may be found in the fact that there was also very little change in the melting peak temperatures of the two polymers after blending.

In the PP/EVA/WP composites, the experimentally observed enthalpies for EVA melting were significantly lower than the calculated values. In comparison, the experimentally observed and calculated enthalpy values for PP melting are almost the same

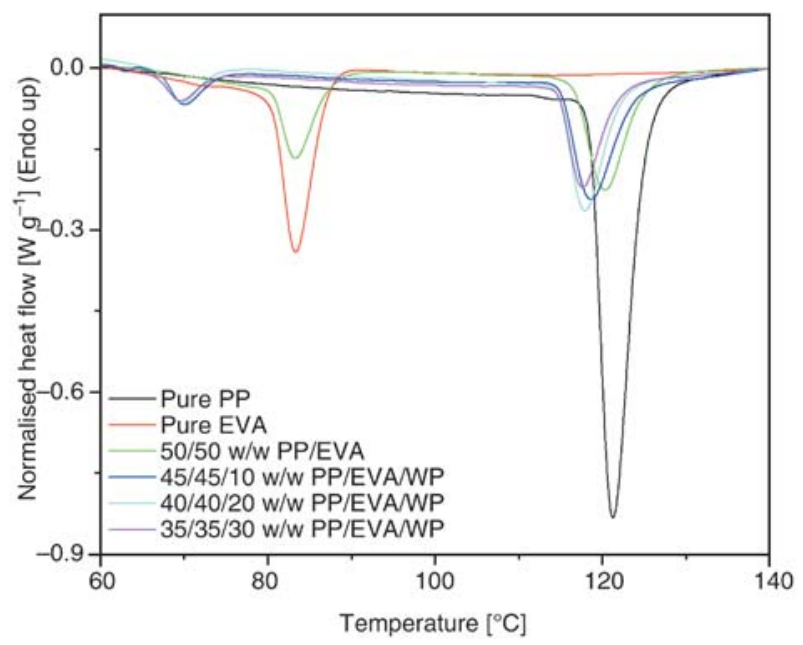

Figure 2. DSC cooling curves of pure EVA, pure PP and $\mathrm{PP} / \mathrm{EVA} / \mathrm{WP}$ blend composites

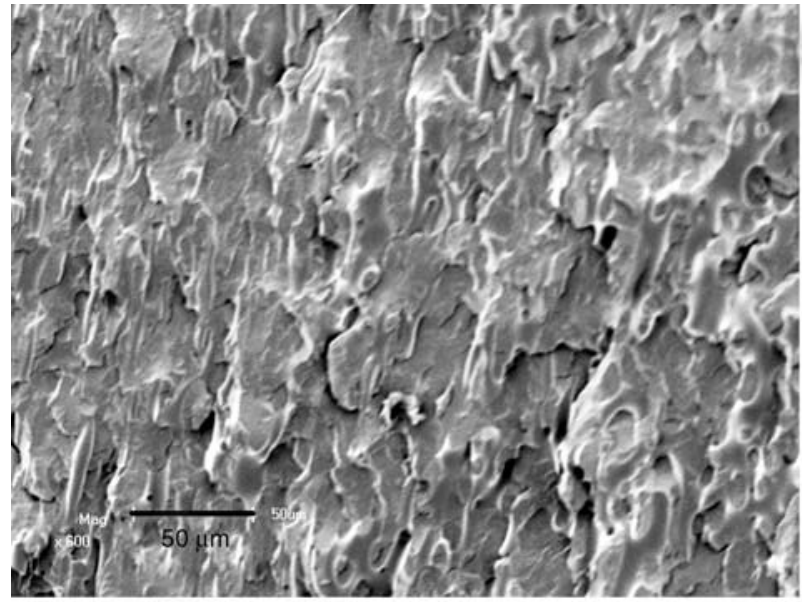

a) for all three investigated composites (Table 1). The peak temperatures of PP melting in the composites are also not significantly different from those of pure PP and blended PP, while those of EVA in the composites are significantly lower than those of pure EVA and blended EVA. This shows that WP is situated primarily in the EVA phase and strongly interacts with EVA. As a result of this interaction, the EVA chains are immobilized by the WP particles, which results in a reduced crystallization of EVA. This conclusion is supported by the positions of the crystallization peaks in Figure 2 that are at significantly lower temperatures for EVA. It has been reported [20] that the addition of cellulosic material to a PP/EVA blend causes a decrease in crystallization, melting and oxidation temperatures, and an insignificant increase in crystallinity of the blend. However, the authors of this paper did not distinguish between the PP and EVA phases in the blend. Salemane and Luyt [15] reported an increase in crystallinity of PP in the presence of WP, and in the absence of a compatibilizer [15].

The SEM photos of the fracture surfaces of the 50/50 w/w PP/EVA blend before and after extraction are shown in Figure 3. Figure 3a shows that it is not possible to see separate PP and EVA phases on the SEM photo of the $50 / 50 \mathrm{w} / \mathrm{w}$ PP/EVA blend; this is in line with observations by Mihaylova et al. [9], who used SEM to study the supramolecular structures of PP/EVA blends. Their SEM microphotographs of the unirradiated blends show that in EVA-rich blends, EVA was the continuous phase, while PP was identified as spherical particles within the blend. When PP was the major phase, PP

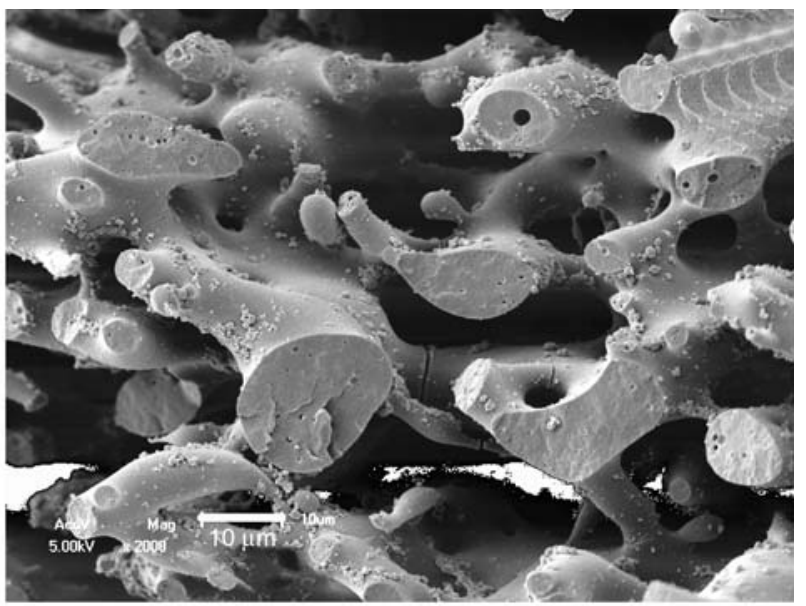

b)

Figure 3. SEM pictures of the fracture surfaces of 50/50 w/w PP/EVA a) before extraction and b) after extraction (2000x magnification) 


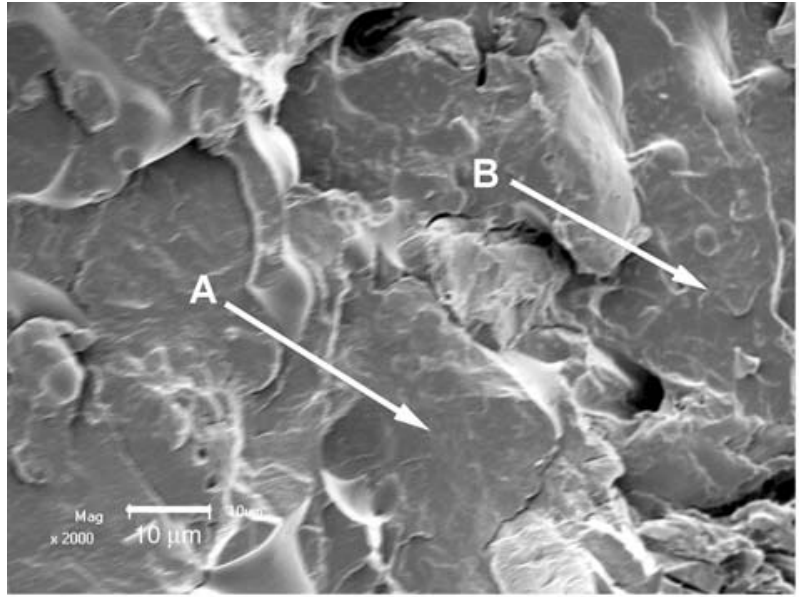

a)

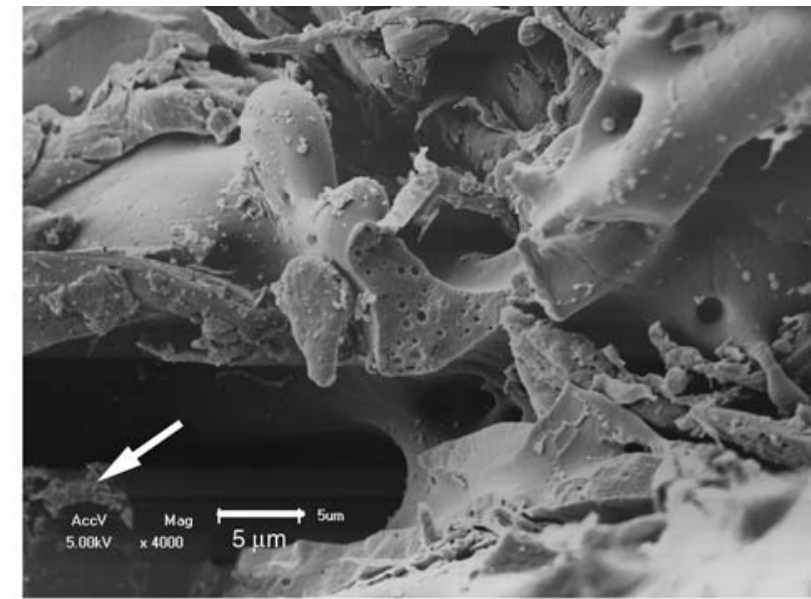

b)

Figure 4. SEM pictures of the fracture surfaces of 40/40/20 w/w PP/EVA/WP a) before extraction and b) after extraction (2000× magnification)

formed the continuous phase, while EVA showed partially coalesced droplets. However, the authors found it difficult to distinguish the two components in the 50/50 w/w PP/EVA blend; although the images could show brittle surfaces (related to PP) and regions where plastic deformations (related to rubbery EVA) have occurred. This finding suggested a co-continuous structure for the 50/50 w/w PP/EVA sample. Gupta et al. [27], in a similar study on PP/EVA blends, observed the same behaviour. The SEM photo of our 50/50 w/w PP/ EVA blend, after extraction in $n$-heptane, clearly confirms this co-continuous structure (Figure $3 b$ ).

The SEM photo (Figure 4a) of the 40/40/20 w/w $\mathrm{PP} / \mathrm{EVA} / \mathrm{WP}$ blend composite before extraction shows WP particles intimately covered by a polymer (arrow A), which probably is EVA (according to the DSC observations). Although the two polymers are not distinguishable in the photo, it may be assumed with some certainty that the smooth phase (arrow $B$ ) consists primarily of PP. The arrow in the SEM photo of the $n$-heptane extracted 40/40/ $20 \mathrm{w} / \mathrm{w}$ PP/EVA/WP blend composite clearly shows the loose WP particle in the hole left by the extracted EVA (Figure 4b). This confirms that the WP particles were primarily located in the EVA phase of the immiscible blend.

DMA storage modulus and damping factor curves of all the investigated samples are shown in Figures 5 and 6. Figure 5 shows that at low temperatures EVA has slightly lower storage moduli than $\mathrm{PP}$, but the difference becomes more significant

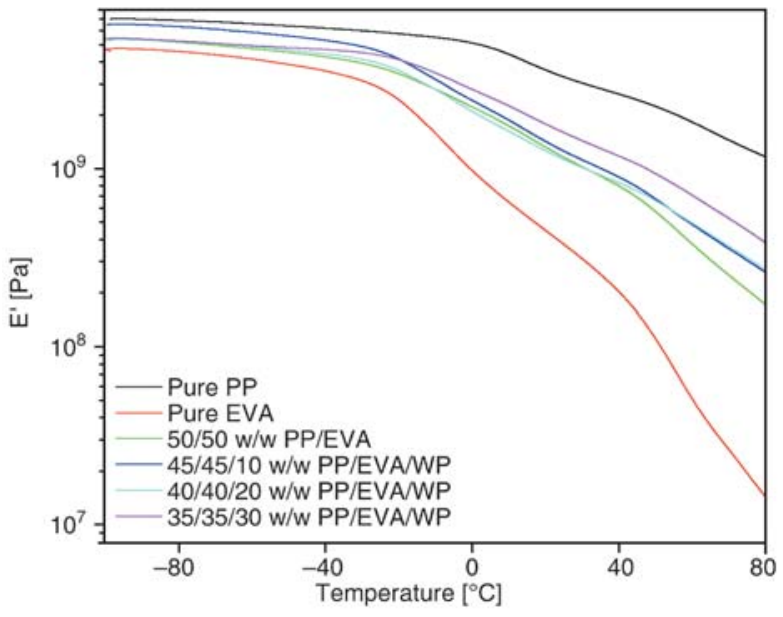

Figure 5. Storage modulus as function of temperature of pure EVA, pure PP, and PP/EVA/WP blend composites

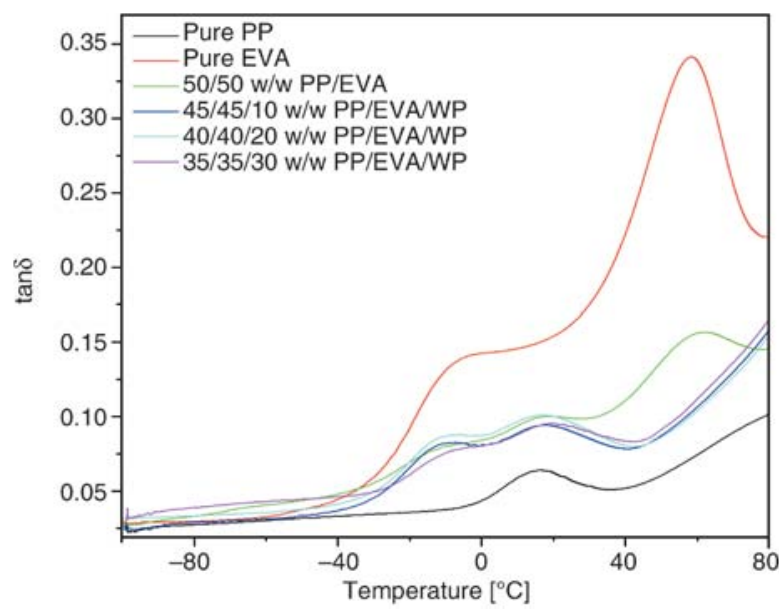

Figure 6. $\tan \delta$ as function of temperature of pure EVA, pure PP, and PP/EVA/WP blend composites 
with increasing temperature. The PP/EVA polymer blend and the WP blend composites have storage moduli between those of pure EVA and pure PP over the whole temperature range. It is interesting that the presence of wood powder does not seem to significantly change the storage moduli, probably because it is concentrated in the EVA phase. The damping factor curve of EVA shows two different transitions, the $\beta$-transition at about $0^{\circ} \mathrm{C}$ and the $\alpha$-transition at about $58^{\circ} \mathrm{C}$ (Figure 6). The $\beta$-transition corresponds to the glass transition of EVA. PP has a $\beta$-transition peak at about $16^{\circ} \mathrm{C}$. This transition corresponds to the glass transition of the amorphous region in PP $[1,22]$. The PP/EVA blend shows all the characteristic peaks of pure PP and pure EVA, indicating complete immiscibility of the two components. In the case of the PP/EVA/WP blend composites, the $\alpha$-transition of EVA is no longer visible, which shows that the interaction between EVA and WP has a significant influence on the interlamellar shear properties of EVA.

Figures 7 and 8 show the FTIR microscopy photo of the 40/40/20 w/w PP/EVA/WP blend composite and the FTIR spectra of pure PP, pure EVA, a $50 / 50 \mathrm{w} / \mathrm{w}$ PP/EVA blend and a 40/40/20 w/w PP/EVA/WP blend composite. The FTIR microscopy photo of the 40/40/20 w/w PP/EVA/ WP composite in Figure 7 shows the formation of three separate phases, a dark area, a darker interface and a light area. FTIR analysis of the light areas gave a spectrum corresponding to that of PP (Figure 8). This observation confirms that WP has no affinity for PP. The dark (a) and interfacial (b) areas gave spectra corresponding to that of 40/

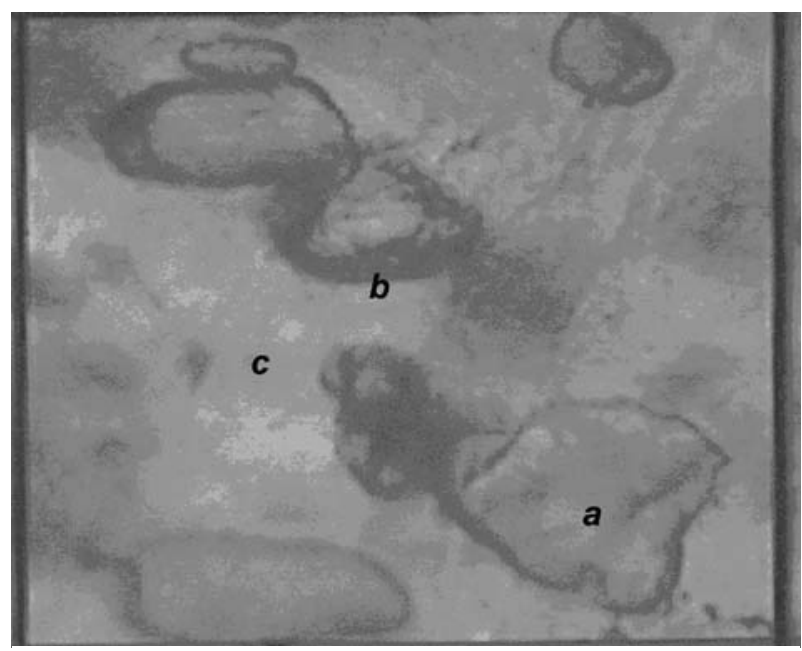

Figure 7. FTIR microscope photo of the 40/40/20 w/w PP/EVA/WP blend composite

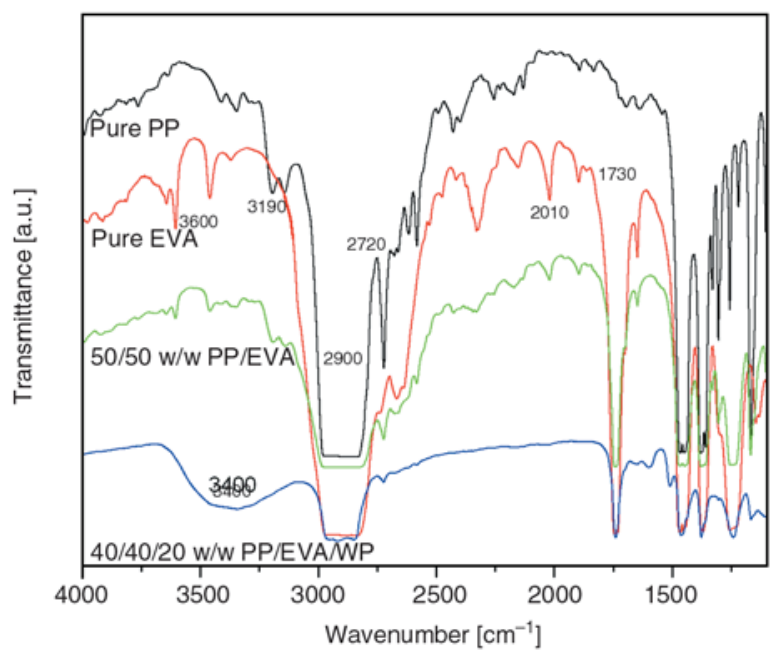

Figure 8. FTIR spectra of pure EVA, pure PP and $\mathrm{PP} / \mathrm{EVA} / \mathrm{WP}$ blend composites

40/20 w/w PP/EVA/WP. The spectrum shows the $-\mathrm{OH}$ peak (around $3400 \mathrm{~cm}^{-1}$ ), indicating the presence of WP, while the other peaks are characteristic peaks of EVA and not PP (Figure 8). All the spectra show strong absorbance peaks around 2850 and $2920 \mathrm{~cm}^{-1}$ that are associated with the $\mathrm{C}-\mathrm{H}$ asymmetric stretching of the polymers. The peak representing the vibration of the $-\mathrm{C}=\mathrm{O}$ ester of the carboxyl group appears at $1750 \mathrm{~cm}^{-1}$ in pure EVA, the PP/EVA blend and the PP/EVA/WP blend composite. The fact that the PP/EVA blend spectrum shows all the characteristic peaks for pure EVA and pure PP, and that no new peaks are observed, indicate the absence of any reaction or interaction between EVA and PP, which supports the SEM, DSC and DMA observations. The lack of vibrational changes in PP/EVA compared to pure PP and pure EVA was also reported by HuertaMartinez et al. [5], who indicated that the vibrational changes of the carbonyl group would be noticed only in miscible blends. The presence of WP in the blend composite is indicated by a strong, broad $-\mathrm{OH}$ functional group stretching vibration around $3400 \mathrm{~cm}^{-1}$. The $-\mathrm{C}=\mathrm{O}$ peak at $1750 \mathrm{~cm}^{-1}$ in the blend composite is much less intense than that in pure EVA and the PP/EVA blend, probably as a result of the $-\mathrm{C}=\mathrm{O}$ interaction with the $-\mathrm{OH}$ in WP. Thermogravimetric analysis (TGA) was used to investigate the thermal stability and degradation of PP, EVA, the PP/EVA blend and the PP/EVA/WP blend composites. The TGA and derivative TGA curves of these samples are shown in Figures 9 and 10. EVA (with two degradation steps) is ther- 


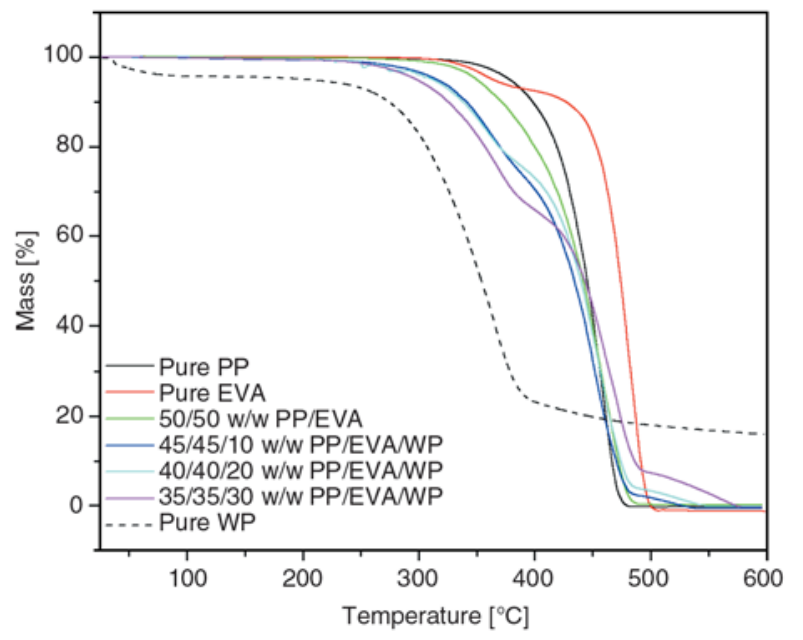

Figure 9. TGA curves of pure EVA, pure PP, WP and $\mathrm{PP} / \mathrm{EVA} / \mathrm{WP}$ blend composites

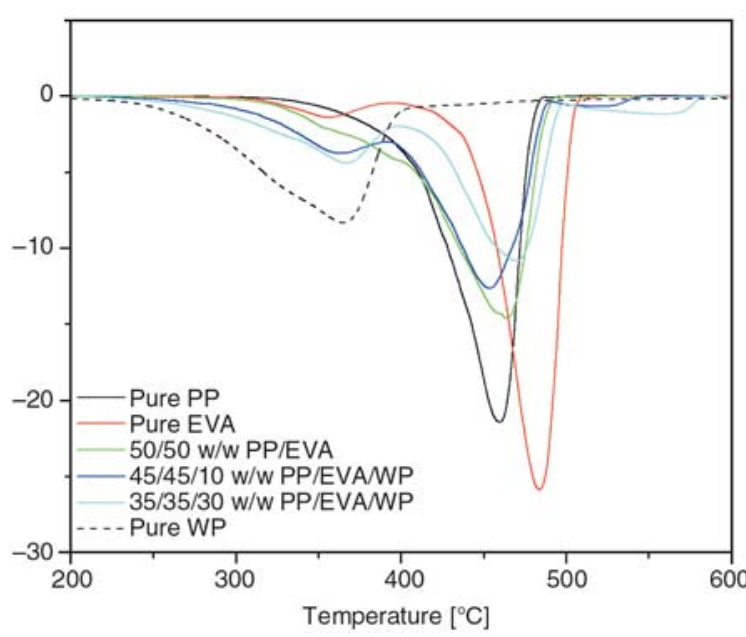

Figure 10. Derivative TGA curves of pure EVA, pure PP, $\mathrm{PP} / \mathrm{EVA}$ blend, WP and PP/EVA/WP blend composites

mally more stable than PP. However, the blend degrades at a slower rate than pure PP due to the influence of the more thermally stable EVA backbone. The blend composites show two degradation steps; the first one is atrributed to the degradation of WP combined with de-acetylation, and the second one is due to the degradation of PP and the EVA backbone. The onset temperatures of the first degradation step of the composites decrease and the intensities of the derivative peaks (Figure 10) increase as the WP content increases. The second degradation step of the composites starts at higher temperatures than that for the 50/50 w/w PP/EVA blend. This may be attributed to the interfacial interaction between WP and the EVA part of the PP/EVA blend. Qui et al. [23] studied the structure and properties of composites of highly crystalline cellulose with PP, and reported that no significant change was observed in the thermal stability of PP in the presence of cellulose due to the lack of compatibility between the two. However, when the system was compatibilized with maleic anhydride grafted PP (MAPP), the thermo-oxidative stability of the PP/cellulose composites was enhanced due to the improvement in interfacial interaction between PP matrix and cellulosic filler, promoted by MAPP. Joseph et al. [26] also reported that the addition of short sisal fibre to PP yielded composites that are more thermally stable than the PP matrix. Another reason for the second degradation step starting at higher temperatures may be the retardation of the evaporation of volatile degradation products due to the char formed during the first degradation step. Peeterbroeck et al. [28] reported a delay in the thermal degradation with the addition of clay to EVA, mainly due to a decrease in the rate of evolution of the volatile products. Duquesne et al. [7] reported that the second degradation step (which corresponds to the decomposition of the polyethylenic fraction) in EVA-nanoclay systems occurred at a higher temperature in the presence of clay. This behaviour was attributed to a diffusion effect, which limited the emission of the gaseous degradation products, resulting in an increase in the thermal stability of the second degradation step of EVA.

The tensile properties of the blend and composites as a function of filler content are presented in Table 2. Generally, the filler plays an important

Table 2. Mechanical properties of PP/EVA/WP blend composites

\begin{tabular}{|c|c|c|c|}
\hline $\mathbf{P P} / \mathbf{E V A} / \mathbf{W P}[\mathbf{w} / \mathbf{w}]$ & $\mathbf{E} \pm \mathbf{S E}[\mathbf{M P a}]$ & $\boldsymbol{\varepsilon}_{\mathbf{b}} \pm \mathbf{s} \boldsymbol{\varepsilon}_{\mathbf{b}}[\boldsymbol{\%}]$ & $\boldsymbol{\sigma}_{\mathbf{b}} \pm \mathbf{s} \boldsymbol{\sigma}_{\mathbf{b}}[\mathbf{M P a}]$ \\
\hline $100 / 0 / 0$ & $498.5 \pm 13.5$ & $26.7 \pm 2.5$ & $29.9 \pm 1.3$ \\
\hline $0 / 100 / 0$ & $38.2 \pm 1.4$ & $535 \pm 12.3$ & $9.9 \pm 0.5$ \\
\hline $50 / 50 / 0$ & $258 \pm 3.5$ & $12.9 \pm 0.1$ & $12.8 \pm 0.1$ \\
\hline $45 / 45 / 10$ & $265 \pm 2.3$ & $10.7 \pm 0.1$ & $8.9 \pm 0.2$ \\
\hline $40 / 40 / 20$ & $272 \pm 3.7$ & $9.7 \pm 0.4$ & $7.7 \pm 0.1$ \\
\hline $35 / 35 / 30$ & $285 \pm 3.5$ & $7.25 \pm 0.1$ & $7.6 \pm 0.2$ \\
\hline
\end{tabular}

$E$ - tensile modulus, $\varepsilon_{b}$ - elongation at break, $\sigma_{b}-$ tensile strength 
role in determining the mechanical properties of lignocellulosic filled thermoplastics [1-5, 20, 26]. The tensile moduli of pure PP and pure EVA are 498 and $38 \mathrm{MPa}$ respectively, and the modulus of the PP/EVA blend is an average of these values (Table 2). This is to be expected, because PP and EVA form a totally immiscible blend (see Figure 3), and the blend will have a tensile modulus to which both polymers contribute equally. Table 2 shows an increase in modulus of the composites with an increase in WP content, because rigid fillers normally increase the stiffness of a composite [23].

The PP/EVA blend has an elongation at break lower than those of the individual polymers, because the interfaces between the two non-compatible polymers form defect points where stress cracking will occur more easily. A further decrease in elongation at break was experienced with increasing WP content, which is normal for these types of composites [13, 18, 19, 23]. It is commonly explained as being due to the restriction in chain mobility of the matrix, and to the filler particles acting as defect points.

The tensile strengths of the composite samples decrease with an increase in WP content. This is probably the result of WP particles locating themselves in the EVA phase. Although the WP has a greater affinity for EVA, and seems to preferably locate itself inside the EVA phase, there will not be enough EVA in the blends with high WP contents, and as a result a fair amount of WP particles may locate themselves at the EVA-PP interface. The tensile strengths of these composites will therefore decrease because of the weak interaction between WP and PP. Kim et al. [25] reported that the tensile strength of WP filled PP composites decreased with increasing bio-flour loading due to the weak interfacial adhesion and low compatibility between the hydrophilic bio-flour and hydrophobic PP.

\section{Conclusions}

PP/EVA/WP polymer blend composites were prepared and their morphology as well as thermal and mechanical properties were investigated. The PP/EVA blend shows immiscibility due to a lack of interaction between PP and EVA. SEM and FTIR microscopy shows in lack of homogeneity as indi- cated by island formation within the blend composite. In the blend composites the WP has a higher affinity for EVA than for PP. This significantly influenced the crystallization behaviour of EVA, which was clearly observed from both the DSC and DMA results. The presence of WP in the PP/EVA blend caused a decrease in the degradation temperature of the first degradation step, which is a combination of WP degradation and EVA de-acetylation. At the same time the degradation temperature of the second step increased, probably as a result of the strong interaction between WP and EVA combined with retardation in the evolution of volatile degradation products. The stress and the strain at break of the blend composites decreased with an increase in WP content, while the modulus increased.

\section{Acknowledgements}

The National Research Foundation in South Africa (TTK2006052300007) and the University of the Free State are acknowledged for financial support of the project.

\section{References}

[1] Jayanarayan K., Thomas S., Joseph K.: Morphology, static and dynamic mechanical properties of in situ microfibrillar composites based on polypropylene/ poly(ethylene terephthalate) blends. Composites Part A: Applied Science and Manufacturing, 39, 164-175 (2008).

DOI: 10.1016/j.compositesa.2007.11.008

[2] Yu L., Dean K., Li L.: Polymer blends and composites from renewable sources. Progress in Polymer Science, 31, 576-602 (2006). DOI: 10.1016/j.progpolymsci.2006.03.002

[3] Si X., Guo L., Wang Y., Lau K-T.: Preparation and study of polypropylene/polyethylene terephthalate composite fibres. Composites Science and Technology, 68, 2943-2947 (2008).

DOI: $10.1016 /$ j.compscitech.2007.11.008

[4] Lou C-W., Lin W-L., Lei C-H., Su K-H., Hsu C-H., Liu Z-H., Lin J-H.: PET/PP blends with bamboo charcoal to produce functional composites. Journal of Materials Processing Technology, 192-193, 428-433 (2007).

DOI: $10.1016 /$ j.jmatprotec.2007.04.018

[5] Huerta-Martinez B. M., Ramirez-Vargas E., MedellinRodrequez F. J., Garcia R. C.: Compatibility mechanisms between EVA and complex impact heterophasic PP-EP $x$ copolymers as a function of EP content. European Polymer Journal, 41, 519-525 (2005). DOI: $10.1016 /$ j.eurpolymj.2004.10.021 
[6] Albano C., Reyes J., Ichazo M., Gonzalez J., Chipara M. I.: Influence of gamma irradiation on the thermal stability of blends with previously treated sisal fibre. Polymer Degradation and Stability, 73, 225-236 (2001).

DOI: $10.1016 / \mathrm{S} 0141-3910(01) 00036-2$

[7] Duquesne S., Jama C., Le Bras M., Delobel R., Recourt P., Gloaguen J. M.: Elaboration of EVA-nanoclay systems-characterization, thermal behaviour and fire performance. Composites Science and Technology, 63, 1141-1148 (2003).

DOI: $10.1016 / \mathrm{S} 0266-3538(03) 00035-6$

[8] Liu Y., Kontopoulou M.: The structure and physical properties of polypropylene and thermoplastic olefin nanocomposites containing nanosilica. Polymer, 47, 7723-7731 (2006).

DOI: 10.1016/j.polymer.2006.09.014

[9] Mihaylova M. D., Nedkov T. E., Krestev V. P., Kresteva M. N.: Supermolecular structures of poly(propylene-co-ethylene)/poly(ethylene-co-acetate) blends irradiated with fast electrons. SEM, SAXS and DSC studies. European Polymer Journal, 37, 21772186 (2001).

DOI: $10.1016 / \mathrm{S} 0014-3057(01) 00118-5$

[10] Mihailova M., Kresteva M., Aivazova N., Krestev V., Nedkov E.: X-ray investigation of polypropylene and poly(ethylene-co-vinyl acetate) blends irradiated with fast electrons: WAXS investigation of irradiated i-PP/EVA blends. Radiation Physics and Chemistry, 56, 581-589(1999).

DOI: 10.1016/S0969-806X(97)00292-2

[11] Suarez J. C. M., Coutihno F. M. B., Sydentricker T. H.: SEM studies of tensile fracture surfaces of polypropylene-sawdust composites. Polymer Testing, 22, 819-824 (2003).

DOI: 10.1016/S0142-9418(03)00017-5

[12] Premphet K., Horanont P.: Phase structure of ternary polypropylene/elastomer/filler composites: Effect of elastomer polarity. Polymer, 41, 9283-9290(2000). DOI: $10.1016 / \mathrm{S} 0032-3861(00) 00303-7$

[13] Uotila R., Hippi U., Paavola S., Seppala J.: Compatibilization of PP/elastomer/ microsilica composites with functionalized polyolefins: Effect on microstructure and mechanical properties. Polymer, 46, 79237930 (2005).

DOI: $10.1016 /$ j.polymer.2005.06.099

[14] Dikobe D. G., Luyt A. S.: Effect of poly(ethylene-coglycidyl methacrylate) compatibilizer content on the morphology and physical properties of ethylene vinyl acetate-wood fiber composites. Journal of Applied Polymer Science, 104, 3206-3213 (2007).

DOI: 10.1002/app.26080

[15] Salemane M. G., Luyt A. S.: Thermal and mechanical properties of polypropylene-wood powder composites. Journal of Applied Polymer Science, 100, 41734180 (2006).

DOI: $10.1002 / a p p .23521$
[16] Lundqiust L., Marque B., Hagstrand P-O., Leterrier Y., Manson J-A. E.: Novel pulp fibre reinforced thermoplastic composites. Composites Science and Technology, 63, 137-152 (2003).

DOI: $10.1016 / \mathrm{S} 0266-3538(02) 00192-6$

[17] Harper D., Wolcott M.: Interaction between coupling agent and lubricants in wood-polypropylene composites. Composites Part A: Applied Science and Manufacturing, 35, 385-394 (2004).

DOI: 10.1016/j.compositesa.2003.09.018

[18] Felix J. M., Gatenholm P.: Effect of transcrystalline morphology on interfacial adhesion in cellulose/polypropylene composites. Journal of Materials Science, 29, 3043-3049 (1994).

DOI: $\underline{10.1007 / \mathrm{BF} 01117618}$

[19] Menyhárd A., Varga J.: The effect of compatibilizers on the crystallisation, melting and polymorphic composition of $\beta$-nucleated isotactic polypropylene and polyamide 6 blends. European Polymer Journal, 42, 3257-3268 (2006).

DOI: $\underline{10.1016 / j . e u r p o l y m j .2006 .09 .003}$

[20] Espert A., Vilaplana F., Karlsson S.: Comparison of water absorption in natural cellulosic fibres from wood and one-year crops in polypropylene composites and its influence on their mechanical properties. Composites Part A: Applied Science and Manufacturing, 35, 1267-1276 (2004).

DOI: $10.1016 /$ j.compositesa.2004.04.004

[21] Keener T. J., Stuart R. K., Brown T. K.: Maleated coupling agents for natural fibre composites. Composites Part A: Applied Science and Manufacturing, 35, 357 362 (2004). DOI: 10.1016/j.compositesa.2003.09.014

[22] Qiu W., Zhang F., Endo T., Hirotsu T.: Preparation and characterization of composites of high crystalline cellulose with polypropylene: Effect of maleated polypropylene and cellulose content. Journal of Applied Polymer Science, 87, 337-345 (2003). DOI: $10.1002 /$ app.11446

[23] Qui W., Endo T., Hirotsu T.: Structure and properties of composites of highly crystalline cellulose with polypropylene molecular weight: Effects of polypropylene molecular weight. European Polymer Journal, 42, 1059-1068 (2006).

DOI: $\underline{\text { 10.1016/j.eurpolymj.2005.11.012 }}$

[24] Bledzki A. K., Gassan J.: Composites reinforced with cellulose based fibres. Progress in Polymer Science, 24, 221-274 (1999). DOI: $10.1016 / \mathrm{S} 0079-6700(98) 00018-5$

[25] Kim H-O., Lee B-H., Choi S-W., Kim S., Kim H-J.: The effect of maleic anhydride-grafted polypropylene (MAPP) on the interfacial adhesion properties of bio flour filled polypropylene composites. Composites Part A: Applied Science and Manufacturing, 38, 1473-1482 (2007). DOI: $\underline{10.1016 / \text { j.compositesa.2007.01.004 }}$ 
[26] Joseph P. V., Joseph K., Thomas S., Pillai C. K. S., Prasad V. S., Groeninckx G., Sarkissova M.: The thermal and crystallization studies of short sisal fibre reinforced polypropylene composites. Composites Part A: Applied Science and Manufacturing, 34, 253-266 (2003).

DOI: $10.1016 / \mathrm{S} 1359-835 X(02) 00185-9$

[27] Gupta A. K., Ratnam B. K., Srinivasan K. R.: Impact toughening of polypropylene by ethylene vinyl acetate copolymer. Journal of Applied Polymer Science, 45, 1303-1312 (1992).

DOI: $\underline{10.1002 / a p p .1992 .070450718}$
[28] Peeterbroeck S., Alexandre M., Jérôme R., Dubois Ph.: Poly(ethylene-co-vinyl acetate)/clay nanocomposites: Effect of clay nature and organic modifiers on morphology, mechanical and thermal properties. Polymer Degradation and Stability, 90, 288-294 (2005). DOI: 10.1016/j.polymdegradstab.2005.03.023 